\section{LA BIOÉTICA HACE FUTURO}

\author{
Alfredo Marcos \\ Universidad de Valladolid \\ ORCID iD: https://orcid.org/0000-0003-2101-5781 \\ amarcos@fyl.uva.es
}

\section{BIOETHICS MAKES FUTURE}

Cómo citar este artículo/Citation: Marcos, A. (2019). La bioética hace futuro. Arbor, 195 (792): a506. https://doi.org/10.3989/ arbor.2019.792n2007
Copyright: (C) 2019 CSIC. Este es un artículo de acceso abierto distribuido bajo los términos de la licencia de uso y distribución Creative Commons Reconocimiento 4.0 Internacional (CC BY 4.0).

Recibido: 30 septiembre 2015. Aceptado: 28 abril 2016.

RESUMEN: Para entrever el futuro de la bioética lo primero que tenemos que pensar es la propia noción de futuro y nuestra relación práctica con el mismo. Expongo aquí a la crítica la idea de un futuro que esté ya de algún modo presente y a la vista. Es esta una idea que desposee al futuro de toda futureidad, una idea, por lo tanto, incoherente. Propongo, a cambio, pensar el futuro como tarea, como agenda, como aquello que no está y ha de ser libremente hecho. En este sentido, resulta inútil tratar de vislumbrar o adivinar el futuro de la bioética, y en cambio es preciso proponernos como tarea la creación de la bioética futura. Vistas así las cosas, la función principal de la bioética no será ya la de deliberar y elegir entre las opciones que se nos presentan, sino la de crear nuevos cursos de acción que protejan y favorezcan mejor la vida en general y la vida humana en particular. Abogo, pues, en este texto, por una bioética de la creatividad y de la laboriosidad, superadora de la bioética de dilemas.

PALABRAS CLAVE: Bioética de dilemas; bioética creativa; elección; creatividad; futuro.
ABSTRACT: To discern the future of bioethics we must first contemplate the very concept of future, as well as our practical relationship with the future itself. Here I will subject to criticism the idea of a future that is already somehow present, and in sight. This idea divests the future of all its futurity, becoming, therefore, inconsistent. I propose to regard the future as a task, a kind of agenda: the future is not in sight, but instead it should be freely done. In this sense, it is useless to try to catch a glimpse or guess the future of bioethics. I would suggest, instead, the task of creating future bioethics. As things stand, the main role of bioethics can no longer be to deliberate and choose among the options presented, but rather to create new courses of action to better protect and promote life in general and human life in particular. Hence, in this paper I advocate a bioethics of creativity, which could overcome many bioethical dilemmas.

KEYWORDS: Dilemmatic bioethics; creative bioethics; choice; creativity; future. 


\section{BIOÉTICA Y FUTURO}

La bioética nació como una disciplina orientada hacia el futuro. La primera vez que aparece la palabra bioética en el título de un libro-Bioethics: Bridge to the Future- lo hace junto a la palabra futuro. Además, la idea de 'puente' sugiere aquí la de 'construcción'. Así se expresa Van Rensselaer Potter en el mencionado libro: "Si hay dos culturas que parecen incapaces de hablar la una con la otra -la ciencia con las humanidades- y si ello es parte de la razón por la que el futuro parece dudoso, entonces posiblemente nosotros podríamos construir un puente hacia el futuro" (Potter, 1971, p. 145)․․ De algún modo está implícita la idea de que el futuro no está ya presente, sino que hay que construirlo.

Este planteamiento conecta inmediatamente con una cierta concepción antropológica, cuya expresión hallamos en los textos del filósofo español Julián Marías. "La ilusión -nos dice el discípulo de Ortega- radica en esa dimensión de la vida humana que he explorado a fondo en la antropología metafísica: su condición futuriza, es decir, el hecho de que, siendo real y por tanto presente, actual, está proyectada hacia el futuro, intrínsecamente referida a él en la forma de la anticipación y la proyección. Esto, claro es, introduce una 'irrealidad' en la realidad humana, como parte integrante de ella, y hace que la imaginación sea el ámbito dentro del cual la vida humana es posible. Si el hombre fuese solamente un ser perceptivo, atenido a realidades presentes, no podría tener más que una vida reactiva, en modo alguno proyectiva [...] Pero el futuro no es real; no es, sino que será; y habría que agregar: acaso" (Marías, 1984, p. 38).

Pero la orientación constructiva o proyectiva de la bioética, arraigada en la propia naturaleza futuriza del ser humano, puede verse frustrada. Sucede cada vez que la bioética opta por metáforas visuales en lugar de manuales; cuando se obsesiona por convertirse en un método de elección entre opciones presentes a la vista, en lugar de preocuparse de crear, de construir nuevos puentes y caminos.

Quizá nos preguntemos qué pueden tener que ver las imágenes del tiempo con las ideas bioéticas. Pero lo cierto es que dichas imágenes condicionan drásticamente la bioética. La imagen más socorrida del tiempo es aquella que lo asimila a una dimensión espacial. Pensamos, así, el tiempo como una línea que recorremos. En esta imagen, la posición del sujeto sobre la línea marca el momento presente, el futuro está al frente y a la vista, mientras que el pasado que- da a nuestra espalda -"la negra espalda del tiempo", escribió Shakespeare ${ }^{2}$. Miramos hacia el futuro y lo vemos allá al frente. Psicológicamente la imagen es tan elemental como potente. Nadie quiere quedarse parado o retroceder cuando ha emprendido camino hacia una meta. La visión del futuro se nos impone, pues, como misión. Debemos avanzar hacia ese futuro que vemos, que algunos con especial claridad y seguridad parecen tener a la vista. Es decir, será bueno todo aquello que tienda hacia ese futuro que vemos, y malo lo que nos paralice o haga retroceder. Quien controle la imagen del futuro controlará también lo que se entiende por bueno y malo. Quien sea capaz de afirmar con mayor convicción hacia dónde vamos, será también quien nos diga hacia dónde debemos ir. Esta es la clásica posición progresista, propia de muchas filosofías modernas.

Por otro lado, quien vea con disgusto la imagen del futuro que se le ofrece, estará tentado de abogar por la paralización o el regreso al pasado, a una supuesta aetas aurea. Será tachado, por supuesto, de retrógrado. Esta fue la posición, por ejemplo, de Platón y es también la de algunos contemporáneos nuestros. Una posición errónea, porque propone algo imposible, como la parálisis o el regreso al pasado, porque supone que "cualquiera tiempo pasado fue mejor"3, lo cual dista mucho de ser obvio, y sobre todo, porque, al igual que el progresismo, da por buena una imagen incorrecta del tiempo.

Con todo, lo más común ha sido pintar el supuesto futuro con los colores de una avanzada y prometeica tecnociencia. El desarrollo y aplicación de la misma se convierte entonces en una especie de obligación de progreso. El problema es que la bioética no puede trabajar con una imagen tan pobre y errónea del tiempo. Para empezar, un futuro que esté ahí delante, a la vista, es un futuro que está ya de algún modo presente, al menos ante una vanguardia de visionarios. Y un futuro presente es una extraña contradicción, como ya demostró Karl Popper al hilo de su crítica al historicismo (Popper, 1957). Es un futuro desposeído de toda su futureidad.

Pensemos, pues, en otra imagen más adecuada para el tiempo, en otra constelación léxica, en otro juego de metáforas. Podríamos, por ejemplo, pensar el tiempo como una serie de círculos concéntricos, el mayor de los cuales es el presente, que en su interior contiene los círculos del pasado, a modo de huella y memoria. En esta imagen, el futuro ni está en parte alguna ni se ve, sino que se hace. Hay que hacerlo. Y puede ser hecho con un cierto margen de libertad. La 
naturaleza y el ser humano están constantemente haciendo el futuro, que no está simplemente a la vista. Hay que crearlo, producirlo, generarlo, actualizarlo. Algo así le sucede al compositor musical, que retiene en el presente la suma integrada de los compases ya escritos, pero aun tiene que crear el próximo, que no está todavía en lugar alguno, ni viene predeterminado, aunque sí condicionado, por los anteriores. El mundo está abierto a innumerables futuros posibles, que vendrán o no en función de nuestras acciones.

Es esta una imagen que armoniza mucho mejor con la cosmología actual. Nuestro horizonte presente contiene, por ejemplo, la huella térmica de una explosión inicial, así como la luz emitida por las estrellas en el pasado. Lo que no contiene es el futuro del cosmos, que está aún por hacer. En esta clave, tiende hacia el futuro, hace futuro, quien más proteja y promueva la vida, quien proteja y promueva en especial la posibilidad y florecimiento de la vida humana (cf. Jonas, 1995), que es tanto como decir quien más trabaje para que el futuro siga estando abierto.

En esta nueva imagen del tiempo, nuestra posición cambia. Lo que tenemos a la vista es el pasado, de él aprendemos para decidir y construir un futuro que está abierto, que está aun por hacer y que ha de ser libremente hecho, porque la simple permanencia en el presente o el regreso al pasado son estrictamente imposibles. Por decirlo de otro modo, vemos el pasado, pero no podemos regresar a él. No vemos el futuro, pero tenemos que hacerlo para poder habitarlo algún día como presente. El pescador en su barca toma los remos con las manos y boga mirando a popa. Más que un carril a seguir, tiene a proa una estela que inventar. Los ojos son nuestro nexo con el pasado, las manos con el futuro, valga la metáfora.

En suma, nos proyectamos siempre hacia el futuro, pero a la vista tenemos solo el pasado. Con la información que este nos da tenemos que apañarnos para ir construyendo un camino, de entre los muchos posibles, al mismo tiempo que caminamos por él. En palabras del poeta español Antonio Machado: "Se hace camino al andar" (Machado, 2001, p. 186). Esta quizá sea la mejor imagen de la posición del ser humano en el tiempo. La línea biográfica e histórica a través de los círculos concéntricos del tiempo la vamos trazando nosotros, no está predeterminada, como sucedía en la vieja imagen del tiempo. Podemos salir del círculo del presente por cualquiera de los infinitos radios del mismo hacia un futuro aún por hacer. $Y$ esta nueva metáfora invalida la vieja retórica del tiempo, que dividía las ideas bioéticas en progresistas y retrógradas, que nos obligaba a decidir dilemáticamente entre ambos polos. Invalida incluso esta jerga inoperante. Ninguna bioética puede ya ser medida por su proximidad a un futuro tecnológico o cultural supuestamente visto por algunos, sino por su capacidad para crear futuro, para abrir futuro. Las propuestas bioéticas han de ser medidas por su capacidad para proteger y promover la vida natural y humana, por su capacidad para proteger y promover la posibilidad y el florecimiento de la misma en un universo abierto.

\section{LA BIOÉTICA DE LOS DILEMAS}

De una errónea imagen del tiempo deriva una concepción dilemática de la bioética. Según esta concepción, la bioética tendría por misión principal la de ayudarnos a deliberar y a elegir entre alternativas dadas como ya presentes. Muchas veces estas alternativas se formulan como dilemas. Pero los dilemas son siempre y en realidad el mismo. O aceleramos o retardamos la marcha hacia el presunto futuro. Como toda línea, la del tiempo tendría una sola dirección y dos sentidos. Cada uno puede elegir en qué sentido empuja el carro de la historia. Aunque la marcha hacia el frente se da por garantizada, en función de la correlación de fuerzas podrá ser más o menos veloz. Es lógico que quienes conciben así el tiempo, como un único carril, piensen la bioética en términos de dilema: o aceleramos la marcha hacia el futuro o la retardamos. Eso es todo.

Pondremos un ejemplo clásico, y después irán apareciendo más. El debate sobre la eutanasia a menudo se configura como un dilema: o bien aceptamos la eutanasia, es decir el hecho de que una persona dé muerte a otra en ciertas condiciones especiales y controladas, o bien aceptamos que el enfermo siga sufriendo a causa de su mal o incluso a causa de los tratamientos que recibe. Una élite de iluminados avizora la primera opción allá al frente, en el futuro, mientras que sitúa la segunda a su espalda, en el pasado. La forma lógica es disyuntiva: $A$ o $B$. La disyunción suele entenderse en términos excluyentes y exhaustivos. Es decir, $A$ y $B$ no pueden darse juntos $y$, por otro lado, entre ambos cubren todo el espectro de los posibles cursos de acción.

Puestas así las cosas, es común adoptar una estrategia argumentativa negativa; es decir, para defender la opción $A$ se ataca o niega la opción $B$. Por ejemplo, si demostramos que el sufrimiento del enfermo no es deseable, incluso que es moralmente inaceptable, entonces, dado que no hay más opciones que $A$ y $B$, no tendremos más remedio que aceptar (tolerar, pro- 
mover, legalizar...) la eutanasia. El esquema lógico y retórico se repite una y otra vez en numerosos debates bioéticos. El paisaje que comienza a aparecer ante nosotros es el de un campo de batalla, en el cual contienden los que empujan la historia hacia un futuro visible contra los que intentan retrasar ese avance. Al parecer, la misión principal de cada agente consiste en atacar con argumentos la posición contraria.

En principio, dichos argumentos son de carácter racional. Las armas con las que se contiende en este campo de batalla son habitualmente los llamados principios de la bioética. Se dice que tal o cual posición viola el principio de autonomía, el de no maleficencia, el de beneficencia o el de justicia, y que es, por lo tanto, inaceptable; lo cual, supuestamente, nos obliga a echarnos en los brazos de la posición opuesta. Por ejemplo, se puede decir que la posición pro-eutanasia viola el principio de no maleficencia, o bien que la posición contraria viola el de autonomía. Por supuesto, las cosas nunca son tan sencillas y la resolución de conflictos éticos mediante la aplicación mecánica de principios es simplemente una quimera. Constituye un logro innegable de la bioética el consenso que existe en torno a los mencionados principios pero, a la hora de fundamentarlos, de dar razón de los mismos, de precisar su contenido y finalmente de aplicarlos, la batalla se recrudece. Si $A$ viola un principio, es posible que $B$ viole otro. Y como el problema se nos ha convertido en un dilema, nos hemos quedado sin salida razonable, salvo la pura apelación a la presunta visión del futuro. O bien habrá que empezar a discutir, ya en otro plano, cómo han de entenderse los principios en cuestión y cuál de los principios, ahora en conflicto, debe prevalecer. Si los defensores de la eutanasia pueden pensar que los principios de no maleficencia y de beneficencia han de ser aplicados en función de las preferencias del sujeto (reduciéndolos, así, en cierto modo, al de autonomía), por su lado, los que son contrarios a la eutanasia pueden argüir que la beneficencia y la no maleficencia tienen un contenido objetivo que no depende totalmente de las preferencias subjetivas. Por supuesto, estas ideas remiten a convicciones muy de fondo y a visiones del mundo. Ahora, los proponentes de cada una de las posiciones parecen verse obligados a atacar no solo la posición contraria en este tema particular, sino toda una cosmovisión.

Por añadidura, en cuanto los dilemas bioéticos tocan la arena política, mediática, académica o empresarial se tornan incluso más agrios y menos racionales. No se trata ya solo de desacreditar la posición contraria, e incluso toda una visión del mundo y de la vida, para establecer la propia, sino que se acude hasta a la argumentación ad hominem. En suma, la bioética corre el riesgo de ser vista así como un campo de batalla, o mejor dicho, como el paisaje después de la batalla. Porque esta es la vía segura hacia el estancamiento intelectual, primero, la decadencia, después, y finalmente la completa irrelevancia social de la bioética. Es cierto que la bioética, tanto en la academia, como en los comités que están sobre el terreno, es muy rica, compleja y multiforme, pero también lo es que, como disciplina, no siempre ha logrado transmitir a la sociedad esta riqueza. Muchos de nuestros conciudadanos tienden a ver la bioética, así, como el paisaje después de la batalla, como un campo poblado de cuestiones estancadas, de dilemas oxidados e irresueltos, de armamento argumental ineficaz y contaminador, de pesada maquinaria administrativa que solo sirve ya pare entorpecer el tránsito. ¿Cómo remediarlo?

En parte se trata de un problema de imagen, de percepción pública, que requiere, en consecuencia, un cambio de metáforas. De la visión del tiempo como una línea hemos pasado a la visión del mismo como una serie de círculos concéntricos. En consonancia con ello, podríamos considerar ahora la imagen de la bioética como un obrador y no como un campo de batalla dilemático. Veremos, así, la bioética como un lugar para la cooperación, para el trabajo en común y, sobre todo, para la producción de algo nuevo y mejor. Si formulamos los problemas como dilemas, la acción propia de la bioética consiste en elegir. Formulados los problemas bioéticos como retos a la creatividad y a la laboriosidad humana, la acción más propia de la bioética será la producción, en lugar de la elección.

Pero, antes de explorar las posibilidades de esta nueva imagen de la bioética, tenemos que decir todavía algo más sobre los dilemas éticos, o más bien sobre nuestra resistencia a los mismos. Entre los más conocidos y estudiados dilemas éticos están los llamados dilemas del tranvía. Dichos dilemas han sido empleados profusamente por varios investigadores. Entre otros, los psicólogos morales Marc Hauser y John Mikhail los han usado en sus investigaciones sobre una posible gramática moral universal ${ }^{4}$. Existen numerosas variantes de los dilemas del tranvía. Podemos tomar dos de ellas a modo de ilustración. Supongamos que alguien se encuentra a bordo de un tranvía que pierde los frenos. El tranvía puede seguir avanzando por la vía que actualmente transita o bien cambiar de vía. En el primer caso resultarán atropellados cinco operarios que trabajan en la vía unos metros más adelante, en el segundo caso resultará atropellado un viandante. 
La opción está en manos de alguno de los ocupantes del tranvía, que puede, simplemente pulsando un botón, desviar o no el tranvía. ¿Qué debe hacer? En otra versión alguien podría parar el tranvía que se dirige hacia los cinco operarios lanzando a la vía, desde un puente, a una persona que se encuentra sentada en el pretil del mismo. De nuevo, ¿qué debe hacer este sujeto que podría evitar cinco muertes produciendo una? Los investigadores expusieron estas y otras variantes del dilema en cuestión a numerosos sujetos de experimentación. A través de los test han llegado a identificar algunas normas morales que parecen ser universales, como por ejemplo que estimamos como moralmente más grave el mal producido por acción que el consentido por omisión, o que valoramos como más grave el mal que se comete mediante contacto directo con la persona dañada.

Ahora bien, el objetivo aquí no tiene que ver con estos resultados, sino con la primera reacción de incomodidad con el dilema que muestra la mayor parte de los sujetos experimentales. De hecho es la misma reacción que probablemente habrán tenido muchos lectores al captar los dilemas que hemos introducido como ejemplos. Se trata de lo que podríamos llamar una resistencia al dilema. Muchos sujetos comienzan a especular con soluciones alternativas que rompan el dilema, hasta que el experimentador les recuerda cuáles son las condiciones estrictas del test: solo hay dos opciones. En la situación experimental esta restricción es necesaria, pero hay que recordar que no rige en la vida ordinaria. Es más, la resistencia al dilema incentiva la creatividad y laboriosidad de los seres humanos. Gracias a dicha resistencia -a veces intensificada incluso hasta la indignación- y a la actividad creativa que desencadena, cada uno de nosotros crece como persona, y la humanidad en su conjunto progresa moralmente. Por ejemplo, la resistencia moral al dilema sufrimiento/eutanasia ha desencadenado todo el trabajo creativo que requiere la línea de los cuidados paliativos.

Hay que admitir que en ciertas ocasiones, quizá en circunstancias de urgencia o de necesidad extrema, el dilema moral puede resultar inevitable, al menos a corto plazo. Y tal vez un dilema forzado pueda resultar también útil como experimento para el investigador. Pero lo que es absurdo es plantear el grueso de los problemas bioéticos, y proyectar el futuro de la disciplina, en términos de dilemas, olvidando nuestra pulsión de resistencia, nuestra capacidad de trabajo y el carácter creativo de la acción humana. Es más, pensamos que la bioética actual, precisamente, tiene que incrementar su resistencia a los dilemas, planteando sus problemas como retos a la creatividad y laboriosidad humana. La imagen social de la bioética será así la de un obrador, antes que la de un campo de batalla.

Hay que admitir también que de un obrador pueden salir panes o pasteles. Y el verbo pastelear tiene en español connotaciones que nadie ignora. Es decir, la superación de los dilemas no debería plantearse como una especie de pasteleo, de simple negociación y consenso entre posiciones enfrentadas para hallar un punto equidistante. Hemos de esperar que de nuestro obrador bioético salgan no solo pasteles, sino principalmente panes auténticos y buenos, es decir genuinas soluciones más que simples apaños.

\section{HACIA UNA BIOÉTICA DE LA CREATIVIDAD Y DE LA LABORIOSIDAD}

Descendiendo ya al terreno de lo concreto, presentaremos, aunque sea someramente, algunos problemas actuales de bioética formulados desde este nuevo enfoque, no como dilemas, sino como retos para la creatividad y laboriosidad humanas. No se pretende, ni mucho menos, elaborar un listado exhaustivo ni una clasificación de los problemas bioéticos, sino presentar una modesta muestra significativa e ilustrativa de los retos actuales. Para que la muestra sea, en efecto, significativa, seleccionamos aquí unas pocas cuestiones bioéticas que podríamos calificar de clásicas, junto con otras que han pasado recientemente a primer plano. Algunas proceden del terreno de la ética ecológica, o macrobioética, mientras que otras se ubican en el campo de la bioética médica o microbioética. La intención es que una vez captado el enfoque creativo de retos, como sustituto del enfoque electivo de dilemas, se pueda aplicar a los numerosos problemas bioéticos a los que nos enfrentamos.

\subsection{Algunos problemas clásicos de bioética}

\subsubsection{Cuidados paliativos}

En pocos debates como en el de la eutanasia se aprecia tan bien la esterilidad de un enfoque dilemático. No entraremos aquí a debatir todas las distinciones técnicas, por otra parte sobradamente conocidas, entre las diversas modalidades de la eutanasia y de la asistencia al suicidio. Vamos al núcleo de la cuestión. Cuando lo planteamos como un dilema nos vemos obligados a elegir entre dos cauces de acción igualmente decepcionantes: o bien consentimos el sufrimiento del enfermo terminal, o bien regulamos la posibilidad de que una persona dé muerte a otra. 
Muchos pensamos que el sufrimiento del enfermo es un mal. $Y$ tal sufrimiento puede proceder de las enfermedades que padece o incluso de un sobretratamiento de las mismas. Pero también pensamos muchos que el principio general de que una persona no debe dar muerte a otra debería estar sometido a las mínimas excepciones posibles. Así, la eliminación de excepciones tradicionales, como la de la pena de muerte, nos parece a muchos un genuino progreso de la humanidad. Mientras que la incorporación de nuevas excepciones supondría, en todo caso, el reconocimiento de un fracaso ${ }^{5}$.

Por suerte, no hay por qué transitar obligatoriamente por uno de los dos sentidos señalados, o resignación ante el sufrimiento o resignación ante la eutanasia. En este tema, la vía creativa que nos saca de un mal dilema se viene desarrollando ya desde hace años gracias al trabajo de muchos profesionales. Vamos a denominarla, de un modo genérico, vía de los cuidados paliativos ${ }^{6}$. En ella se incluyen también ideas y prácticas como las del testamento vital, limitación del esfuerzo terapéutico, órdenes de no reanimación, prevención del suicidio, sedación paliativa y terminal... Esta nueva línea de acción ante el sufrimiento ha de ser entendida en un sentido integral, que incorpora todas las medidas de cuidado, confort y acompañamiento de la persona en todas sus dimensiones. Es cierto que el desarrollo de los cuidados paliativos supone un reto para nuestra creatividad y laboriosidad, y requiere además ciertas inversiones, mientras que la resignación al sufrimiento o a la eutanasia resultan ambas opciones más baratas y acomodaticias.

\subsubsection{Maternidad libre}

Desde hace más de una década, en España, el número de abortos intencionados, o dicho en lenguaje oficial, de embarazos interrumpidos voluntariamente, se mantiene en torno a los cien mil anuales. En números redondos se han producido un millón de abortos en los últimos diez años. La reducción de dicho número constituye un reto ético importante no solo para los profesionales de la sanidad, sino también para la sociedad en general. Es más, en mi opinión, la disminución del número de abortos en los países en los que dicha práctica está legalizada, debería contar como un dato positivo a la hora de calcular el correspondiente Índice de Desarrollo Humano (IDH). Y algo análogo se podría decir respecto de las comunidades autónomas españolas. Sería deseable respaldar el esfuerzo que algunas están haciendo en la reducción del número de abortos ${ }^{7}$.
Para ser claro diré que, en mi opinión, lo idóneo sería el respeto hacia toda vida humana en cualquiera de sus fases. Pero el argumento que quiero exponer aquí entiendo que podrá ser compartido también por otras muchas personas que están lejos de considerar la vida humana como igualmente valiosa en todas sus fases. Se trata de un argumento que busca la practicidad y el acuerdo amplio, pues creo que la mayor parte de nuestros conciudadanos estará de acuerdo en que en principio es bueno reducir el número de abortos, dado que detrás de cada uno de ellos hay siempre sufrimiento para la embarazada y para el no nacido.

No obstante, hace ya más de medio siglo que la cuestión del aborto está socialmente bloqueada por un planteamiento dilemático del problema. De hecho, una de las posiciones clásicas se suele denominar pro-choice. Al hablar aquí de choice (elección) parece que ya estamos construyendo el problema como un dilema, en lugar de pensarlo como un reto. Esta terminología parece suponer que la mujer embarazada tiene ante sí dos opciones entre las que ha de elegir. Por decirlo de modo muy simple, habría de elegir entre sus legítimos intereses y la vida que lleva en su seno. Pero ¿es que una salida creativa, que respete ambos valores, no es, en muchos casos, ni siquiera pensable? Creo que sí, y por eso preferiría hablar de una posición pro-libertad, más que pro-elección. Ahora bien, desde mi punto de vista, si aumentase realmente la libertad de las mujeres, el número de abortos descendería considerablemente. El altísimo número en que se vienen produciendo indica, en mi modesta opinión, que muchos de ellos no son realmente voluntarios, por más que el lenguaje oficial se empeñe en llamarlos así. Dicho de otro modo, creo que quien elige con libertad habitualmente elige a favor de la vida y no en contra. Es decir, la posición pro-libertad y la posición pro-vida en realidad no se oponen, sino que se complementan, o bien podrían llegar a complementarse si tomásemos este problema como un reto a la creatividad y a la laboriosidad, y no como un mero dilema de elección.

Veamos con más detalle los números que nos sirve el Ministerio de Sanidad. Podemos dejar a un lado los abortos producidos por riesgos para la vida o salud de la embarazada y los que se producen por riesgo de anomalías fetales, que en su conjunto no llegan al 10\%. Vamos, pues, al centro de la cuestión, donde están más del $90 \%$ de los casos, donde de hecho se podría reducir drásticamente el número de abortos $^{8}$. Estos son los que se producen a petición de la embarazada, y tras los que podemos suponer que 
hay en el fondo motivos de tipo socioeconómico. No es difícil conjeturar que un número significativo de estos abortos podría evitarse si la mujer dispusiese de información clara y de apoyos eficaces. A falta de tales apoyos e información, se puede entender que la decisión no se produce realmente en condiciones de plena libertad.

Al señalar la falta de libertad que puede estar afectando a muchas mujeres que abortan, no hablamos ya del aborto coercitivo practicado en algunos países, ni del aborto selectivo, inducido por ejemplo por las políticas chinas de hijo único ${ }^{9}$. Hablamos de la falta de apoyo económico en nuestra propia sociedad, de las dificultades laborales (desempleo, inestabilidad, discriminación, salarios bajos...); hablamos de las dificultades para la conciliación de la vida familiar y laboral, de las dificultades con la vivienda, la sanidad o la escolarización, de la presión social o familiar o de pareja ejercida sobre la mujer, de la desinformación (por ejemplo debida a la dificultad para acceder a ecografías realistas); hablamos de las deficientes políticas de apoyo a la familia ${ }^{10}$, así como de las leyes obsoletas de adopción y acogimiento...

Revirtiendo estas tendencias, el número de abortos provocados podría disminuir. Dichas tendencias se pueden revertir mediante campañas de comunicación y de rechazo del estigma social que se cierne, por ejemplo, sobre quien deja sus hijos en adopción, mediante apoyos efectivos a la maternidad en el plano económico, laboral, sanitario y escolar, mediante la protección de la mujer frente a toda presión y violencia del entorno, mediante la información adecuada, mediante nuevas leyes de adopción y acogimiento más ágiles y flexibles, con fórmulas más abiertas... Parece, en efecto, que planteadas así las cosas tenemos ante nosotros auténticos retos a nuestra creatividad y laboriosidad ${ }^{11}$.

\subsubsection{El diálogo médico-paciente}

Otro reto bioético que nadie puede obviar es el que plantea la llamada relación médico-paciente, entendida esta en un sentido muy genérico, que incluye al resto de las profesiones sanitarias y al sistema de salud en su conjunto. En este terreno, las sociedades occidentales contemporáneas han ido evolucionando desde una medicina paternalista, en la que primaba el principio de beneficencia, hacia una atención sanitaria en la que cobra protagonismo el principio de autonomía. Esto, obviamente, no supone un problema, sino un progreso, siempre que los principios se equilibren y no pasemos del paternalismo extremo a la medicina defensiva o a la medicina a la carta; siempre que el paciente no pase a ser simplemente un cliente o usuario y el médico o el sistema de salud su proveedor. Desde el punto de vista filosófico, lo que parece preocupante es que los principios de autonomía y beneficencia acaben por confundirse completamente, de modo que se entienda el segundo en términos por entero subjetivos. Así, el bien del paciente quedaría reducido simplemente a la preferencia del cliente o usuario. Incluso la interpretación subjetivista podría llegar a afectar al principio de no maleficencia, de modo que no sería malo algo para un paciente a menos que él lo considerase como tal, hasta el punto de que el proveedor de servicios sanitarios se vería compelido a actuar contra las buenas prácticas médicas si así lo pidiese un usuario.

Parece claro que no deberíamos vernos obligados a elegir entre un paternalismo extremo y una forma de medicina defensiva, a la carta o totalmente subjetivista. Lo inadecuado de uno de estos dos polos no hace mejor al otro. Ahora bien, para salir del dilema, una vez más, se requiere poner en marcha nuestra creatividad y laboriosidad. Gran parte del esfuerzo creativo en este punto ha ido dirigido al establecimiento y regulación del consentimiento informado. Creo que la dirección es acertada, pero con ciertos matices. El consentimiento informado y la tutela adecuada son, en efecto, las líneas más prometedoras para la reconversión de este dilema en reto pero, en mi opinión, no se puede fiar todo a la regulación exhaustiva. En las relaciones médico-paciente siempre quedarán aspectos que hemos de confiar a la prudencia de las partes. La tendencia actual parece apuntar a una proliferación, quizá excesiva, de los documentos de consentimiento informado, aplicables cada vez a más prácticas médicas. Los comités éticos tienen sobre su mesa cada día más documentos de este tipo para examinar e informar. Además, muchos de estos se están volviendo prolijos y minuciosos, como si se pretendiese lograr a través de los mismos la regulación completa de la relación médico-paciente y la seguridad jurídica plena.

Aquí resulta muy oportuno recordar la advertencia que nos hace Hans Jonas: el requisito del consentimiento informado puede quedar en un simple trámite administrativo si la investigación y la asistencia no se producen en términos generales en un contexto ético adecuado. Según afirma Jonas, "el consentimiento [...] aún no significa la total solución del problema [...] los controles pueden atenuar el problema, pero no superarlo" (Jonas, 1997, p. 90). Jonas se refiere a que hace falta algo más que controles formales. Hace falta el 
reconocimiento de la dignidad de las personas ${ }^{12}$, así como la presencia de virtudes en los miembros de la sociedad, en los médicos e investigadores, en el resto del personal sanitario, en los gestores, en los pacientes... "La sociedad -afirma Jonas- no puede permitirse la falta de virtud en mitad de sí misma" (Jonas 1997, p. 85, cursiva en el original). Así pues, según Jonas, existen condiciones para el correcto funcionamiento de un sistema sanitario que son imprescindibles pero que no son formalmente exigibles y tal vez ni siquiera susceptibles de regulación. Se trata de las virtudes y del carácter propio de los agentes.

El ambiente en el que se desenvuelven los pacientes y los profesionales de la salud ha de ser un ambiente informado por determinadas virtudes, que van desde la sinceridad y lealtad hasta la amabilidad, dedicación, respeto a la dignidad de las personas, y que culminan en la prudencia. Cada uno de los que actúan en el sistema, desde la dirección política y técnica, hasta los profesionales y los pacientes, ha de desarrollar las virtudes propias de su función o posición, de lo contrario el sistema funcionará mal, por más regulación y normativa que se ponga en circulación. Sin embargo, dichas virtudes, que han de informar el carácter de los agentes, no son exigibles formalmente. Dicho de otro modo, siempre se pueden salvar las exigencias formales como trámites carentes de contenido real. Siempre, claro está, que los agentes implicados estén dispuestos a ello. Por ejemplo, el consentimiento informado con demasiada frecuencia se toma como un simple papel que ha de aparecer firmado para la seguridad jurídica de las partes. Visto así, el documento puede resultar un trámite vacío de contenido real. Todo ello nos habla de la importancia de la práctica del consentimiento informado, más que del papel en el cual queda finalmente plasmado. La práctica solo será correcta, solo servirá para salir de un mal dilema, el que se da entre paternalismo extremo y medicina defensiva, si los sujetos han desarrollado las virtudes necesarias. La creatividad y laboriosidad en este caso han de ir orientadas al reconocimiento de la dignidad, al fomento y desarrollo de esas virtudes y, con ello, a la excelencia de las prácticas.

\subsubsection{Ecología humana}

Una de las bases históricas de la bioética es la ética médica, la otra es la ética ambiental o ecológica, lo que a veces se denomina macrobioética. Existen numerosos problemas ambientales con implicaciones éticas. Algunos autores han hablado incluso de la letanía de los problemas ambientales: contaminación, agotamiento de los recursos, riesgos para la biodi- versidad, cambios climáticos, etc. Con frecuencia se plantean estos problemas en términos dilemáticos que podríamos recoger bajo esta formulación general: o sostenibilidad ambiental o crecimiento económico. En algún momento se pensó que el problema ético consistía precisamente en la elección entre estos dos polos. Y los defensores de cada uno de ellos se reclamaban como los auténticos arúspices del futuro. Así, durante los años setenta y ochenta del siglo pasado se puso de moda la idea del crecimiento cero. Ya en los noventa parecía claro que la paralización del crecimiento económico no contribuiría positivamente a la sustentabilidad ambiental, sino más bien al contrario. Además de generar miseria entre los humanos, provocaba graves daños ambientales y nos privaba, de paso, de los recursos económicos imprescindibles para hacer frente a dichos daños. Se puso entonces en circulación la idea de desarrollo sostenible, que rompe el dilema y propone una dirección de búsqueda creativa ${ }^{13}$. El desarrollo sostenible trata de producir soluciones nuevas, más que de elegir entre desarrollo o sostenibilidad.

En nuestros días, estamos dando pasos incluso hacia la superación de la idea de desarrollo sostenible. Se trabaja ya en la integración de la idea de desarrollo sostenible con la idea de desarrollo humano. Esta última procede de la teoría económica del premio Nobel Amartya Sen, inspirador del Índice de Desarrollo Humano que publica Naciones Unidas. Tenemos aquí un ejemplo claro del cambio de planteamiento que venimos propugnando para la bioética. Se ha dado en las cuatro últimas décadas un evidente progreso en la configuración de los problemas ambientales. Ya no los vemos como simples dilemas en los que se nos obliga a escoger entre la salud del medio ambiente y la prosperidad de las personas, entre sustentabilidad y desarrollo. Ahora vemos los problemas ambientales como retos para la creatividad humana. No se trata simplemente de elegir entre $A$ y $B$, sino de construir caminos que antes no existían, de crear una auténtica ecología humana que favorezca el desarrollo humano sostenible ${ }^{14}$. Por supuesto, es más laborioso crear algo nuevo que elegir entre lo ya dado, por ello la creatividad ha de ir unida también en este caso a la laboriosidad.

\subsection{Algunos problemas bioéticos de reciente aparición}

\subsubsection{Experimentación animal}

A caballo entre la ética ecológica y la ética médica se halla la cuestión animalista, que recientemente ha cobrado una gran presencia académica y mediática. 
Respecto a la experimentación con animales hemos tendido a formular los problemas también en términos de dilemas. En general pensamos que o bien aceptamos el sufrimiento animal o bien renunciamos a las utilidades que los animales nos aportan en muy diversos terrenos, desde el productivo al médico.

¿Se pueden construir salidas creativas al problema? De hecho, se están dando los pasos hacia ellas desde varios frentes. Desde la filosofía, desde el derecho y desde la metodología de la experimentación están apareciendo líneas de pensamiento y de acción creativas que pueden cambiar la formulación del problema, de modo que pase de dilema a reto. En el terreno filosófico estamos trabajando en el reconocimiento de valor inherente a los seres vivos $y$, en especial, a los animales. Los animales carecen de la dignidad que sí tenemos las personas, pero no son meras herramientas o instrumentos a nuestro servicio y albur. Cada ser vivo, y en especial cada animal, posee un valor propio, independientemente del valor utilitario que pueda tener para nosotros, y en función del mismo hemos de regular el trato que merece (cf. Cortina, 2009; Marcos, 2013; Marcos, 2014). Desde el campo del derecho se vienen promoviendo desde hace años normativas que mejoran la protección y el bienestar de los animales, reduciendo considerablemente el sufrimiento de los mismos en la cría, transporte y sacrificio, así como en el caso de los animales de compañía y en los de uso experimental. En este último campo, el de la experimentación con animales, se está desarrollando la llamada estrategia de las tres erres (reemplazar, reducir, refinar), que concilia los legítimos intereses de la investigación biomédica con el reconocimiento del valor inherente de los vivientes (cf. Garcés y Giraldo, 2012) ${ }^{15}$. Desde mi punto de vista, la legislación animal se fundamenta mejor en las ideas de protección y bienestar que en la idea de derechos de los animales. Esta última resulta enormemente problemática, como he sostenido en varios artículos (Marcos, 2007; Marcos, 2013; Marcos, 2014). Por supuesto, los problemas están lejos aún de una perfecta resolución y, sobre todo, de una solución que contente a todos los agentes implicados pero es un hecho que se está trabajando, más allá de los dilemas, en diversas líneas creativas.

\subsubsection{Experimentación con células troncales y clonación humana}

Volviendo al puro terreno de la biomedicina, podemos considerar ahora los problemas éticos que suscita la investigación y uso médico de las células troncales (también llamadas células madre o stem cells). Hemos tendido en primera instancia a formular estos problemas en términos de dilemas. Más tarde, este tipo de formulación dilemática ha ido cediendo el paso a un planteamiento en términos de retos creativos. Como es sabido, las células troncales pueden ser obtenidas a partir de diversos tejidos del organismo humano. Algunas tienen más potencial que otras para la división indefinida y para la diferenciación. Una fuente posible de células troncales son los embriones humanos. Las células troncales embrionarias provienen del blastocisto preimplantatorio, tienen la capacidad de dividirse en cultivo indefinidamente, sin diferenciarse, y también la de diferenciarse hacia cualquiera de las tres capas germinales aun después de un prolongado periodo de cultivo. A partir de estas propiedades, se pensó que podrían ofrecer posibilidades terapéuticas prácticamente ilimitadas para la regeneración tisular. Sin embargo, el uso de embriones humanos como simple material experimental de laboratorio, con la consiguiente manipulación y destrucción de muchos de ellos, suscita problemas de carácter ético al menos a una buena parte de la población y de la comunidad científica. Es muy fácil plantear esta situación como un dilema, y, de hecho, así ha sido presentada en innumerables ocasiones por parte algunos científicos, políticos y medios de comunicación: o bien experimentamos con embriones humanos o bien consentimos el sufrimiento de tantos y tantos pacientes cuyas enfermedades no encontrarán cura.

Por suerte, otros científicos se han resistido al dilema y han trabajado en vías de investigación realmente creativas. Lo han hecho por diversos motivos, que van desde lo ético a lo puramente técnico. El uso de embriones humanos como material de laboratorio despierta, claro está, ciertas reservas éticas en mucha gente pero, además, es que las células troncales de origen embrionario presentan dificultades de carácter técnico, por su tumorogenicidad, riesgo de contaminación con productos de origen animal y difícil compatibilidad genética con el receptor. Por supuesto, se puede emprender una especie de huida hacia adelante y tratar de solventar este último problema mediante técnicas de clonación humana ${ }^{16}$. Pero en esta línea, las dificultades éticas y técnicas no se reducen, sino que aumentan, como parece obvio (incluso sin necesidad de recordar el famoso escándalo de Woo-Suk Hwang).

En vista de todo ello, algunos científicos decidieron plantear la cuestión como un reto a la creatividad: se negaron a emplear embriones humanos en sus experimentos pero al mismo tiempo buscaron vías alterna- 
tivas para la obtención de células troncales con suficiente potencial terapéutico. Quizá el más destacado de estos científicos sea el japonés Shinya Yamanaka (cf. Yamanaka, 2012; Gámez 2013), que recibió en 2012 el premio Nobel en Fisiología y Medicina "por el descubrimiento de que células adultas pueden reprogramarse para ser convertidas en pluripotentes"17. Las investigaciones de Yamanaka han permitido la producción de células troncales pluripotentes inducidas (iPS) a partir de las cuales se han podido poner en marcha ya algunos ensayos clínicos. Con este tipo de células troncales se pueden superar las dificultades de compatibilidad genética. Además, con ellas se disipan las reservas éticas, pues evitan la instrumentalización de los embriones humanos ${ }^{18}$.

Aunque se ha visto que la investigación con embriones humanos carece de interés terapéutico, recientemente se ha autorizado en el Reino Unido el uso de estos embriones como material de laboratorio sobre el cual probar la nueva técnica de edición genética denominada CRISPR-Cas9. Aquí los problemas bioéticos se multiplican. Para empezar, se autoriza la aplicación de la técnica sobre los embriones sobrantes (human surplus embryos). Es chocante la propia idea de que algunos embriones humanos -en función de no se sabe qué criterio- están de más o son sobrantes. Pero hay que calificarlos como "sobrantes" para poder establecer, como se hace en la citada autorización, la obligación de que sean destruidos en fases tempranas de su desarrollo. Y la obligación de que los embriones editados sean destruidos pronto se establece, precisamente, para dificultar que estos seres humanos experimentales Ileguen a desarrollarse hasta fases más avanzadas, lo cual generaría una comprensible alarma social. Obsérvese, además, que la manipulación genética de estos embriones no tiene ninguna finalidad terapéutica ni mejorativa para los mismos, sino simplemente experimental; se trata de usarlos -y después desecharlos- para acumular conocimiento científico sobre el desarrollo embrionario temprano y sobre el proceso de implantación. ¿Qué sucederá cuando se quiera investigar el desarrollo humano en fases más avanzadas?, ¿habrá que autorizar entonces la implantación de embriones editados y su gestación hasta fases avanzadas?, ¿habrá que obligar entonces a su eliminación?, ¿y así, hasta dónde? Obviamente, esta alarmante espiral indica que es mucho mejor buscar una vía de investigación más creativa, que no nos obligue a optar entre la parálisis científica o la burda manipulación y destrucción de seres humanos en distintas fases de su desarrollo embrionario o fetal.

\subsubsection{Terapia y mejora humana}

Retomemos ahora lo que se ha sugerido unas líneas más arriba. Quizá la biotecnología pueda servir no solo para curar, sino también para mejorar a los seres humanos. Esta es una de las cuestiones que más literatura bioética está generando en los últimos años. De hecho, la biomedicina actual está en disposición de traspasar el umbral de la terapia para entrar en el terreno de la supuesta mejora humana (human enhancement); en cierta medida, ya hay zonas de la medicina que están cerca del campo de la mejora, como, por ejemplo, la medicina estética o la deportiva, al menos en algunos de sus usos. Por otra parte, el propio concepto de terapia, que depende obviamente de los conceptos de salud y de enfermedad, tiene bordes difusos y posee cierta variabilidad histórica y cultural. Hechas estas salvedades, la cuestión ahora no está precisamente en los bordes difusos de la terapia ni en su posible deslizamiento, sino en el proyecto consciente y ambicioso de cambiar drásticamente la propia naturaleza humana por medios biotecnológicos para llevar al ser humano más allá de lo humano. El problema bioético al que me refiero es el que han puesto sobre la mesa los pensadores transhumanistas y posthumanistas.

Se entiende hoy día por human enhancement, o mejora humana, el intento de sobrepasar los límites naturales del ser humano mediante una serie de antropotecnias ${ }^{19}$. Las referidas antropotecnias, en conjunto, abarcan cuatro grandes ámbitos: nano, bio, info y cogni. Con frecuencia este conglomerado se conoce mediante las correspondientes siglas NBIC, o bien como CT (Converging Technologies), o incluso como HET (Human Enhancement Technologies).

Los aspectos en los que se busca la supuesta mejora del ser humano abarcan desde las capacidades físicas e intelectuales hasta las emociones, la longevidad y prolongación de la juventud o la mejora moral. Los procedimientos pueden ir desde la modificación de la dieta hasta la modificación de estructuras moleculares u orgánicas, modificaciones permanentes de bases genéticas, empleo de diversas sustancias químicas, desarrollo de prótesis motoras o sensoriales, externas o internas, en forma de hardware o de software, potenciación del crecimiento de la corteza cerebral... Se piensa, más allá de las posibilidades terapéuticas, en las aplicaciones militares, laborales, deportivas, estéticas, o en la potenciación de las capacidades intelectuales, como por ejemplo la memoria, en la gestión de los estados afectivos y de nuestra interacción con las máquinas. 
Uno de los problemas básicos que se ha presentado en este tipo de proyectos de investigación consiste precisamente en definir qué es un ser humano y qué podría contar como una mejora del mismo. Ambas cuestiones están muy relacionadas, y en la medida en que modifiquemos drásticamente la naturaleza humana mediante la intervención técnica, difícilmente podremos saber ya qué es mejor y qué es peor. En las prácticas de terapia no se prescinde del concepto de naturaleza humana. De hecho, se apoyan en él. El médico no quiere "mejorar" la temperatura de los seres humanos, sino devolver la de su paciente a los 36 o 37 grados que son normales para un ser humano sano. Una práctica tecnológica que pretende ir más allá de la naturaleza humana destruye de paso los criterios de valoración. En consecuencia, difícilmente se puede llamar mejora. Se trataría más bien de un cambio sin componente axiológico. $Y$ en realidad, de un cambio a peor, pues la pérdida del componente axiológico, de la posibilidad misma de valorar, supone ya una pérdida de valor pues, en palabras de Hans Jonas, la mera posibilidad de valor es ya un valor (Jonas, 1995, pp. 95-96). Parafraseando a Jonas podríamos decir ahora que el tránsito hacia la imposibilidad de valor es ya un disvalor.

El caso del deporte nos sirve aquí de excelente ejemplo ilustrativo. Hasta el momento, los valores del deporte residían en la naturaleza de los atletas y en su capacidad de entrenamiento, de colaboración en equipo y de esfuerzo. Si las condiciones se modifican mediante cualquier forma de doping, transfusiones de sangre, y no digamos intervenciones genéticas, selección eugenésica o implantes mecánicos o informáticos, entonces toda la actividad deportiva se desvirtúa, carece de mérito y queda vacía de valores. Dicho de otra forma, se habría hecho imposible el deporte como tal. Por eso las federaciones sancionan determinadas prácticas como fraudulentas. No solo para custodiar la igualdad de condiciones en una competición leal, sino para preservar el mismo sentido y existencia de la actividad. Por eso en el deporte paralímpico sí se aceptan ciertos tipos de prótesis, como las sillas de ruedas en baloncesto, porque permiten recuperar algo parecido a la movilidad natural. Pero sin este criterio de naturaleza humana, el human enhancement aplicado al deporte sencillamente acaba con el sentido y los valores de esta actividad, y en última instancia con la actividad misma. La deconstruye.

La crítica a los proyectos de supuesta mejora humana ha venido desde varios frentes (Habermas, 2002; Fukuyama, 2002; Marcos, 2010), pero la de- fensa ante las críticas se ha presentado casi siempre de modo dilemático, como un juego de todo o nada: o bien aceptamos cualquier antropotecnia o bien renunciamos a la mejora humana (cf. Savulescu y Bostrom, 2009). Hasta tal punto este dilema ha cobrado importancia que la última sociología sostiene que la política en un futuro próximo se estructurará en función de la actitud de cada cual hacia la biotecnología y el transhumanismo. Los ejes tradicionales, izquierda-derecha, o conservadores-liberales, quedarán obsoletos y serán sustituidos por el eje precaucionistas-proaccionistas (precautionaries-proactionaries), valgan los neologismos (Fuller y Lipinska, 2014). Los unos defenderán un uso restringido o nulo de las antropotecnias, mientras que los otros abogarán por la implantación irrestricta de las mismas.

Frente a esta nueva dicotomía, es posible pensar en innumerables vías para mejorar la vida humana sin necesidad de perder la naturaleza humana que nos orienta y sirve de guía normativa. La línea de resistencia al dilema se sitúa aquí en el umbral de la naturaleza humana. Ahora bien, las reservas frente a una operación de cambio profundo de la naturaleza humana no son en absoluto reservas frente a todas las aplicaciones biotecnologías. Hemos de descartar como excesivamente simplistas dos actitudes ante las mismas, la actitud tecnologista y la actitud neoludita. El tecnologismo resulta acrítico y es una amenaza para la naturaleza humana. Mientras que el rechazo de la técnica es antropológicamente insostenible.

Así pues, las antropotecnias han de ser juzgadas no en bloque, sino una a una. Y este juicio, que nos permite, por ejemplo, valorar como positivo el implante de una prótesis biónica en una persona mutilada y como negativo el intento de producir humanos por clonación, requiere como criterio orientador el de la naturaleza propia del ser humano. Aquí la clave consiste en obviar la supuesta mejora del ser humano y adoptar en cambio como labor y reto la mejora de la vida de los seres humanos. Ahora bien, proponer aplicaciones antropotécnicas, discernir entre las mismas y desarrollar solo las que de veras mejoren la vida de las personas, requiere más creatividad y trabajo que la simple aceptación o negación en bloque de todas las nuevas antropotecnias.

\subsubsection{Neuroética}

El espectacular desarrollo de las neurociencias desde la década de los noventa del siglo pasado ha influido sobre todos los campos del saber. Hasta tal punto es así, que podemos afirmar que nos hallamos en medio 
de una auténtica moda neuro. No hay disciplina que se precie que no haya intentado ganar prestigio anteponiendo a su nombre este prefijo. La ética no podía ser una excepción. Así, desde principios del presente siglo se ha empezado a hablar de neuroética. Ante la irrupción de esta nueva rama del saber, algunos han querido ponernos de nuevo ante una estructura de dilema, con uno de los polos del mismo situado presuntamente en el futuro y el otro en el pasado. Recordemos: conforme a la vulgata positivista, la religión ha sido superada por la filosofía y esta por la ciencia. De modo análogo, la neuroética habría llegado para sustituir a la ética filosófica, que a su vez habría superado ya la moral religiosa y sapiencial. Por fin, asuntos tales como el bien y el mal, la libertad humana, la responsabilidad, la justicia, la felicidad, el sentido de nuestras vidas y otros del mismo tenor, tradicionalmente acaparados por la filosofía, la literatura, el arte y la religión, podrán recibir un tratamiento científico riguroso, se dice. Según esto, conforme avance la neuroética, iremos prescindiendo de la filosofía, así como de las tradiciones religiosas, sapienciales y literarias que torpemente venían guiando a la humanidad hasta la arribada de la ola neuro. Si se acepta este planteamiento, surge la obligación de optar: o bien nos ponemos del lado del futuro, en el cual la ética filosófica será sustituida y superada por las neurociencias, o bien intentamos a la desesperada retardar este movimiento. Parece que la ética solo puede elegir entre la sumisión a las neuriociencias o el simple desprecio de las mismas.

Pero claro está que hay otra forma de entender la neuroética, como un lugar acogedor para el diálogo y la mutua escucha, para la colaboración entre las neurociencias y la ética. Si vemos así las cosas, más que elegir, tendremos que ponernos a construir ese lugar, ese difícil y prometedor territorio interdisciplinario. No aspiramos aquí a la sustitución, que suele implicar empobrecimiento de perspectivas, sino a la cooperación, y a lo que la tradición hermenéutica llama fusión de horizontes. Las neurociencias seguirán, así, siendo lo que son, una parte dinámica y apasionante de las ciencias naturales, mientras que la ética ha de conservar su carácter filosófico y sapiencial. En estas condiciones de mutuo respeto, la comunicación entre ambas será, sin duda, tan laboriosa como beneficiosa para las dos y sobre todo para la familia humana
Podemos concretar esa colaboración en un doble sentido. Se puede trazar una ética de la neurociencia. Será de gran ayuda para investigar y aplicar médicamente la neurociencia con el máximo respeto a la dignidad de todos los seres humanos y al valor del resto de los vivientes. También tenemos una neurociencia de la ética, que nos muestra las bases biológicas que posibilitan y condicionan, sin llegar a determinar, nuestra acción moral ${ }^{20}$.

\section{CONCLUSIÓN}

Hemos hecho una somera revisión de algunos de los problemas éticos con los que actualmente nos enfrentamos. Algunos de ellos son ya tradicionales pero al parecer no hemos conseguido encauzarlos a satisfacción de todos. También nos hemos referido a los de más reciente aparición en el panorama de la bioética. No es, por supuesto, un relato exhaustivo de las cuestiones bioéticas, ni mucho menos, pero sí resulta significativo en un cierto sentido. Hemos aprendido que todos estos problemas pueden ser planteados como dilemas de elección entre dos posiciones dadas, una que supuestamente se sitúa en un futuro que algunos dicen ver y otra que intenta frenar la marcha inevitable hacia esa visión (o espejismo). En ese caso, la bioética se convierte en una especie de campo de batalla en el que la mejor táctica consiste en buscar los flancos débiles del adversario. Sabemos, gracias a la experiencia cotidiana y a las pruebas empíricas llevadas a cabo por la psicología moral, que es muy frecuente entre nosotros una cierta resistencia al dilema cuando ambos lados del mismo nos resultan ingratos. Esta resistencia a veces se prolonga en una actitud de trabajo creativo encaminada a producir una posición nueva y mejor que las dos previamente dadas. Podríamos llamar héroes de esta actitud, por ejemplo, al premio Nobel Shinya Yamanaka y a los profesionales de los cuidados paliativos. Cuando la bioética asume este tipo de trabajo, se transforma de campo de batalla en obrador, pasa de elegir a crear, se libera de una errónea imagen del tiempo y de un planteamiento dilemático. Bajo la inspiración de esta imagen hemos reconstruido los problemas, no ya como dilemas, sino como retos para la creatividad y laboriosidad humanas, retos para una bioética empeñada en hacer futuro. 
1. Véase en este mismo número el artículo de Evandro Agazzi, El estatuto epistemológico de la bioética, en el que se hace una original revisión de los orígenes y epistemología de la bioética.

2. The Tempest, acto 1, escena 2: "What seest thou else in the dark backward and abysm of time?"

3. Puede consultarse este verso de Jor ge Manrique, incluido en Coplas por la muerte de su padre, en: www.cervantesvirtual.com/obra-visor/obracompleta--0/html/ff6c9480-82b1-11dfacc7-002185ce6064_4.html

4. Un extenso y riguroso informe sobre es tos experimentos puede verse en Asla, 2016, cap. 3 y cap. 4 . Existe también trabajo empírico reciente sobre las implicaciones neurológicas de estos dilemas. "En resumen, se ha constatado que en situaciones abstractas en que predomina el componente consecuencialista se activa preferentemente la zona cortical, mientras que en situaciones con más implicaciones directas, personales y emocionales lo hace el cerebro profundo, amígdala y sistema límbico; además se constata que dilemas que hacen entrar en conflicto estos dos sistemas, activan también la circunvolución cingulada anterior" (Marcos, 2015, p. 408).

5. Así lo ha entendido el Parlamento Británico en su rechazo del suicidio asistido. Se produjo en sesión de 11 de septiembre de 2015, por 330 votos frente a 118 . Muchos parlamentarios entendieron que la aceptación del suicidio asistido podría funcionar como sutil mecanismo de presión precisamente sobre las personas más vulnerables.

6. Véase a este respecto y en este mismo número el texto de Victoria Espinar, Los cuidados paliativos en el final de la vida, aspectos clínicos y éticos.

7. Por poner un ejemplo, la tasa de abortos provocados por cada mil mujeres en edad fértil es prácticamente el doble en Asturias que en La Rioja, con datos de
2013. Ello parece indicar que en la primera de estas comunidades hay todavía mucho margen de mejora en este terreno. Pueden consultarse los datos actualizados en la página web del Ministerio de Sanidad: https://www.mscbs.gob. es/profesionales/saludPublica/prevPromocion/embarazo/tablas_figuras.htm

8. Añadamos a esto el dato de que el $80 \%$ de los abortos provocados se dan en mujeres de edades comprendidas entre los 20 y los 40 años. Es decir, en la gran mayoría de los casos no se trata de adolescentes ni de mujeres en edades extremas de su fertilidad.

9. Frente a estos tipos de aborto, la comunidad internacional ha permanecido en general bastante inactiva. Solo hace unos años, en 2007, se produjo en el Senado norteamericano un voto contrario al aborto coercitivo. Sobre aborto selectivo por razón de sexo puede verse: https://es.wikipedia.org/wiki/Aborto_selectivo_por_sexo

10. Según el último Informe sobre la protec ción social de la familia en España, publicado en 2015 por el Instituto de Política Familiar, nuestro país es gravemente deficitario en este terreno en relación con los demás países de su entorno; de hecho, nuestro país tiene una de las prestaciones por hijo a cargo más bajas de Europa, 24 euros, frente a una media europea de 91 (informe disponible en: http://www.ipfe.org/Espa\%C3\%B1a/Documentos/Protecci\%C3\%B3n_Social).

11. La reflexión de Ignacio Sánchez Cámara, en este mismo número, trata precisamente sobre El bioderecho y la protección jurídica de la vida: el caso del aborto.

12. Sobre la dignidad de las personas y su función crucial en la relación médicopaciente escribe en este número Roberto Andorno: La dignidad humana como principio biojurídico y como estándar moral de la relación médico-paciente.

13. La década de los setenta del siglo $X X$ estuvo marcada por la Conferencia de
Estocolmo (1972) y el Informe del Club de Roma, realizado por Denis Meadows y publicado por el MIT en 1972. Este informe, titulado Los límites del crecimiento, abogaba por la fórmula del "crecimiento cero". El crecimiento cero fue probablemente un objetivo desacertado. Significativamente, en 1992, aparece un nuevo Informe Meadows del Club de Roma, más ponderado, bajo el título de Más allá de los límites del crecimiento.

14. El concepto de ecología humana es abordado en este número por Luca Valera, en su artículo Ecología humana: nuevos desafios para la ecología y la filosofía. Puede verse también al respecto Valera y Marcos, 2014

15. National Centre for Replacement, Reduction and Refinement of Animals in Research, What are the 3Rs? Accessible en: http://www.nc3rs.org.uk/the-3rs

16. Francisco Ayala aborda en este número los problemas bioéticos que suscita la clonación humana y, en general, la nueva eugenesia: ¿Clonar humanos? Límites de la eugenesia.

17. The Nobel Prize in Physiology or Medicine 2012: "For the discovery that mature cells can be reprogrammed to become pluripotent". Accessible en: http://www.nobelprize.org/nobel_prizes/medicine/laureates/2012/

18. Natalia López Moratalla aborda en este número la bioética de la investigación con células troncales: La investigación con células troncales y la creatividad científica.

19. Los problemas bioéticos de la supuesta mejora humana son tratados aquí por Elena Postigo, en su artículo Bioética y transhumanismo desde la perspectiva de la naturaleza humana.

20. Estos temas son abordados por extenso en el artículo de Adela Cortina y Jesús Conill titulado Bioética y neuroética. 
Asla, M. (2016). La gramática moral universal. Pamplona: Eunsa.

Cortina, A. (2009). Las fronteras de la persona. El valor de los animales, la dignidad de los humanos. Madrid: Taurus

Fukuyama, F. (2002). El fin del hombre: consecuencias de la revolución biotecnológica. Barcelona: Ediciones B.

Fuller, S. y Lipinska, V. (2014). The proactionary imperative. A foundation for transhumanism. Nueva York: Palgrave Macmillan.

Gámez, J. A. (2013). Investigación con células troncales: racionalidad cientifica y ética. [Tesis doctoral inédita]. Universidad de Navarra: Pamplona.

Garcés, L. F. y Giraldo, C. (2012). La experimentación científica con animales. Revista Lasallista de Investigación, 9 (1), pp. 159-166.

Habermas, J. (2002). El futuro de la naturaleza humana. Barcelona: Paidós.
Jonas, H. (1995). El principio de responsabilidad. Barcelona: Herder.

Jonas, H. (1997). Técnica, medicina y ética. Sobre la práctica del principio de responsabilidad. Barcelona: Paidós.

Machado, A. (2001). Poesías completas. Barcelona: RBA.

Marcos, A. (2007). Política animal. Revista Latinoamericana de Bioética, 7 (12), pp. 60-75.

Marcos, A. (2010). Filosofía de la naturaleza humana. Eikasia. Revista de Filosofía, 6 (35), pp. 181-208.

Marcos, A. (2013). New Philosophical Basis for Animal Policy. Per la Filosofia, XXX (88/89), pp. 109-118.

Marcos, A. (2014). Naturaleza humana y derechos de los animales. En: Diéguez, A. y Atencia, J. M. (eds.). Naturaleza animal y humana. Madrid: Biblioteca Nueva, pp. 161-185.

Marcos, A. (2015). Neuroética y vulnerabilidad humana en perspectiva filosófica.
Cuadernos de Bioética, XXVI (3), pp. 397-414.

Marías, J. (1984). Breve tratado de la ilusión. Madrid: Alianza.

Popper, K. (1957). The poverty of historicismo. Londres: Routledge \& Kegan Paul.

Potter, R. (1971). Bioethics: Bridge to the Future. New Jersey: Prentice Hall.

Savulescu, J. y Bostrom, N. (eds.) (2009). Human Enhancement. Oxford: Oxford University Press.

Valera, L. y Marcos, A. (2014). Desarrollo humano sostenible: una visión aristotélica. Isegoría, 51, pp. 671-690. https:// doi.org/10.3989/isegoria.2014.051.07

Yamanaka, S. (2012). Induced pluripotent stem cells: past, present and future. Cell Stem Cell, 10 (6), pp. 678-684. https:// doi.org/10.1016/j.stem.2012.05.005 